\title{
Inverted Open Innovation Distribution Model
}

\section{Colin Keogh}

\section{University College Dublin}

Potential competing interests: The author(s) declared that no potential competing interests exist.

An innovation model mapping the process of reacting to an external driving problem, accounting for problem moderators, insourcing of technology and external Intellectual property, refining based around a specific boundary conditions then generating a number of innovative outcomes for dissemination via open source distribution, via dedicated channels or through new business ventures.

An example use case would be the Open Source Ventilator project started in 2020 to combat Covid-19.

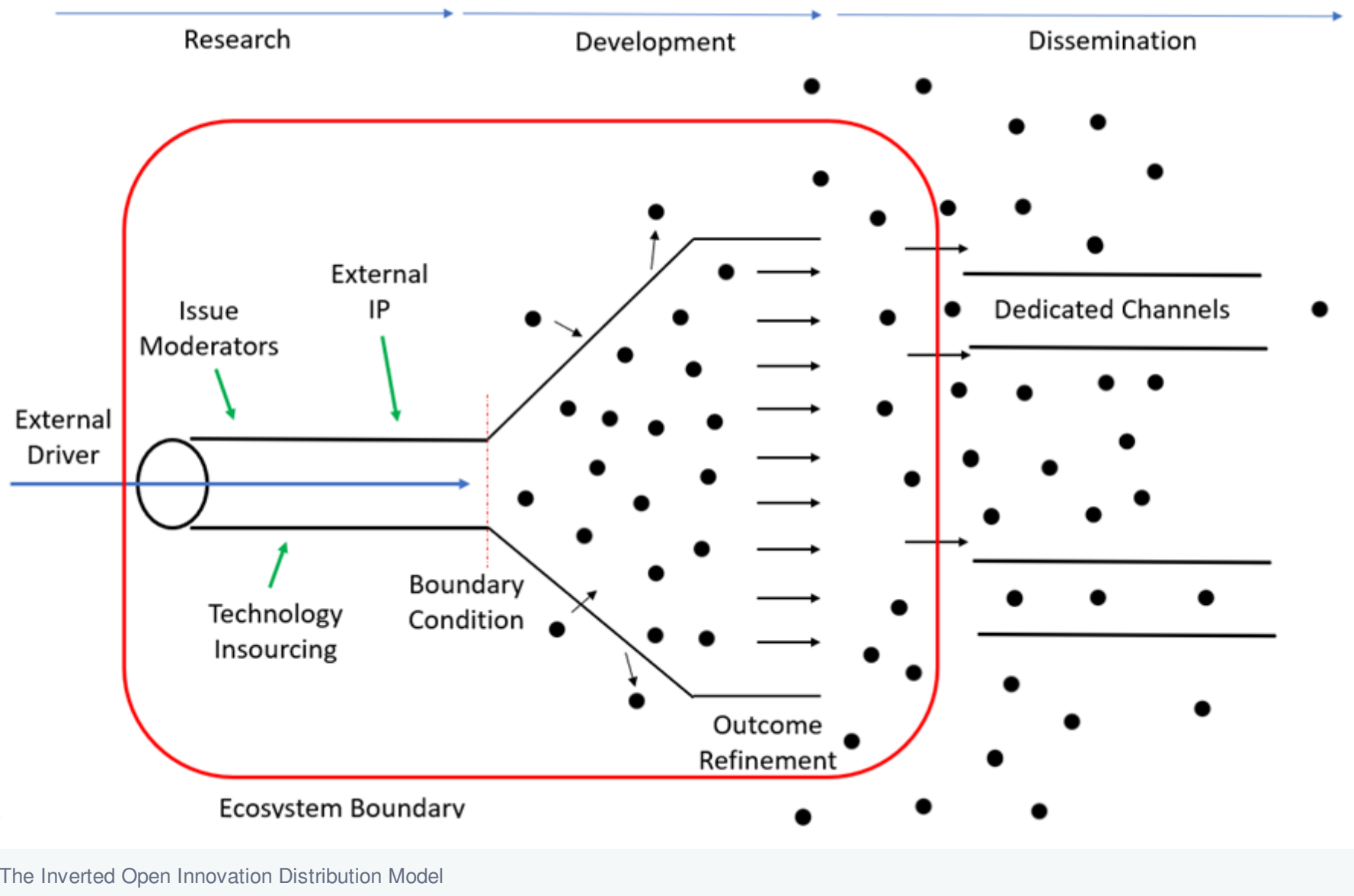

